\title{
Fossilized ethics
}

\author{
The ethical issues surrounding Burmese amber expose a tangle of problems within twenty-first century \\ palaeontology, which has not fully reckoned with its genesis as a colonial science. This editorial accompanies \\ an update to Nature Portfolio policy which takes a first step towards combatting parachute science in \\ palaeontological, archaeological and geological fields.
}

$\mathrm{T}$ he last few years have seen a rise in science news coverage and palaeontological community concerns regarding Burmese amber. This fossil material contains a treasure trove of mid-Cretaceous life found only in Myanmar but has been subject to widespread humanitarian concerns. In this issue we publish three Correspondences that document the complex community views on the subject and help chart a path forward for the best use of this material.

Shuo Wang and colleagues articulate the value of Burmese amber as a scientific resource, opposing the outright ban on studying and publishing amber fossils advocated by the Society of Vertebrate Paleontology in 2020 while emphasizing that it is right that acquisition of new specimens should cease until the current humanitarian crisis in Myanmar is resolved. Paul Barrett, Zerina Johanson and Sarah Long of London's Natural History Museum remind us that not only are ethical questions at stake in the research and publication of Burmese amber, but legal ones too: Myanmar has at least two extant, seemingly conflicting laws, one of which permits the sale and export of amber as a gemstone, while the other prevents the export of fossil material, and it is not clear which takes precedence. As such they argue for caution even when working with samples obtained prior to 2017, which is when the Myanmar military may have begun to profit from amber sales according to United Nations Human Rights observers. Finally, Zin-Maung-Maung-Thein and Khin Zaw, two Myanmar scientists, recognize the complications in navigating Myanmar's amber laws and recommend a pragmatic solution. They suggest that those who buy amber exported as a gemstone may do so in good faith, but when fossils of interest are identified within, researchers should report to authorities (government, museum and university departments) in Myanmar to obtain permission for further work. Most importantly, they note that this work should involve, and be co-authored by, local researchers. Shockingly, a presentation at last year's Palaeontological Association Annual Meeting from Emma
Dunne and Nussaïbah Raja-Schoob estimated, from 30 years of bibliometric data, that no English-language publication on Burmese amber had Myanmar co-authors.

Burmese amber makes for an unusual scenario created by the dual (and conflicting) gemstone and scientific values of the specific material, and is wrapped up in an ongoing humanitarian conflict of horrific proportions. Given this, resolving heritage and gemstone laws may understandably not be a priority in Myanmar right now. But as scientists there attempt to continue with their work under unimaginably difficult conditions, the international community owes them both humanitarian support and a more equitable future for collaborative research. The complexities of the situation with Burmese amber prevent a one-size-fits-all policy at this stage but as editors we will continue to monitor the situation closely and, in the interim, support the pragmatic solution suggested by Zin-Maung-Maung-Thein and Khin Zaw of notifying in-country authorities and collaborating with local researchers.

As Wang and colleagues note, while Burmese amber has become notorious, comparable concern for palaeontological specimens acquired in other ethically troubling contexts has arguably been lacking. This may be changing as practices of 'parachute' or 'helicopter' research within a broad range of scientific fields, including palaeontology, come under increased scrutiny from researchers and the media alike. Parachute science occurs when scientists, typically from the Global North, travel to field sites, typically in the Global South, extract data (such as fossils, archaeological materials or samples of extant taxa) and leave, without collaborating with local researchers whether through project design, by citing local research, or co-authoring. In a worryingly high number of cases scientists may even, whether knowingly or unknowingly, have exported samples in contravention of local and national laws in the countries in which they conduct their fieldwork, as the recent case of the
Brazilian feathered dinosaur Ubirajara jubatus illustrates. In another case, the holotype of the Mexican shark fossil Aquilolamna milarcae may have been purchased illegally by a private collector. As commenters in many of these news stories note, such scenarios can often be avoided where local researchers are involved in work from the get go, as Zin-Maung-Maung-Thein and Khin Zaw recommend for Burmese amber. They note in their Correspondence that equitable collaboration has been possible for many palaeontological projects in Myanmar to date, so there is no reason it shouldn't be possible for amber. More broadly speaking, productive and ethical collaboration should be feasible across palaeontology (and indeed ecology and evolution fields beyond this), facilitated by hubs intentionally designed to foster collaboration between local and international scientists. In 2019, we published a Comment from Zeresenay Alemseged and colleagues about the Eastern African Association of Palaeoanthropology and Palaeontology (EAAPP) that articulated the importance of such hubs. Note that in the time since publication of this piece, the organization underwent a name change from the 'East African' to 'Eastern African' Association, explicitly to refute the colonialist overtones and history of 'East Africa' as a relic region of empire, as in, for example, British East Africa.

As a first step in combatting parachute research, this editorial accompanies an update to Nature Portfolio's research policy for reporting and materials availability requirements for geological, archaeological and palaeontological research. The updated policy explicitly mandates that both collection and export of samples should be in accordance with local and national laws. The policy also requires deposition of such materials (including three-dimensional scans, where possible) within a recognized museum, collection or accessible repository to permit free access by other researchers in perpetuity. This policy update will be accompanied by new questions on our reporting summary and editorial policy checklists, to help ensure that published 
papers in all Nature Portfolio journals handling palaeontological, archaeological or geological materials detail appropriate sample collection, avoiding some of the pitfalls of parachute research outlined in the previous paragraph.
These are first steps, and we do not anticipate that they will solve all the complex problems pertaining to Burmese amber specifically or parachute research more broadly, which is a practice that both Nature Ecology \& Evolution and journals across the Nature Portfolio will work towards eliminating in the future.

Published online: 4 June 2021

https://doi.org/10.1038/s41559-021-01493-1 